\title{
Algumas considerações acerca da medicina estética
}

\author{
Some considerations about aesthetic medicine
}

Francisco Romão Ferreira ${ }^{1}$

${ }^{1}$ Laboratório del novações em Terapias, Ensino e Bioprodutos, Instituto Oswaldo Cruz, Fiocruz. Av. Brasil 4365,

Abstract In this article, we will discuss some aspects of the construction of the meanings concerning the body from the scientific speech which was modeled based on modern thinking and became thehegemonic thinking of some sectors of themedical field. M eanings attributed to the body bring questions that come from other areas of the social life and those questions will build the aesthetic parameters which will be part of the identity construction, in the relation with the body itself, subjectivity and healthcare. We will describe some moments of the construction of the modern scientific thought and how this thought became hegemonic, influences the common sense, naturalizes identity construction and how dealing with the body, interferes in the healthcare, show a division among some sectors of the biomedicine, reinforce an specific type of medical rationality and makes an epistemic base and principle (theoretical and discursive) to some sectors connected to aesthetic medicine and aesthetic surgeries.

Key words Body, Aesthetic medicine, Scientific speech, M edical rationality, H ealth
Resumo N esteartigo, abordaremos alguns aspectos da construção de sentidos acerca do corpo a partir do discurso científico que se moldou com o pensamento moderno e se transformou no pensamento hegemônico dealguns setores da área médica. Ressaltaremos que os sentidos atribuídos ao corpo incorporam questões oriundas deoutrasáreas da vida social evão moldar os parâmetros estéticos que influenciam a construção da identidade, a relação com o próprio corpo, a subjetividade e os cuidados com a saúde. Descreveremos alguns momentos dessa construção do pensamento ci entífico moderno, a forma como este pensamento se torna hegemônico, influencia o senso comum, naturaliza a construção da identidade e a forma de lidar com o corpo, interfere nos cuidados com a saúde, expõe uma divisão entre alguns setores da biomedicina, reforça um tipo específico de racionalidade médica e serve de base epistêmica e fundamentação (teórica e discursiva) para al guns setores ligados à medicina estética e às cirurgias estéticas. Palavras-chave Corpo, M edicina estética, Discurso científico, Racionalidade médica, Saúde 
Introdução

Nos dias atuais, os valores e os saberes que atuam na construção da identidade e nos cuidados com a saúde são influenciados por parâmetros cada vez mais efêmeros e imprecisos. Os cuidados com o corpo e a manutenção da saúde são atravessados por sentidos e discursos que incorporam preocupações estéticas, com a beleza, a imagem e a forma física, ese encontram aparentemente muito distantes das principais discussões da Saúde Pública. Pensar os sentidos atribuídos ao corpo e os cuidados com a saúde significa pensar também neste terreno volátil da subje tividade, da beleza, da forma física, ou seja, pensar nesse universo de questões que extrapolam as questões tradicionais do campo da saúde e constituem a percepção atual do corpo, do conceito de saúde ou do que venha a ser saudável.

Os discursos sobre o corpo se inserem em um processo mais amplo, que possui relação com outros discursos realizados, imaginados ou possíveis. Quando nascemos, os discursos já estão em processo e somos nós que entramos nesse processo, eles não se originam em nós ${ }^{1}$. As palavras e os enunciados não possuem sentido neles mesmos, o sentido éatribuído ou utilizado de acordo com o sujeito que fala, com o contexto da fala, sua situação, a posição que ocupa, sua posição diante dos valores aceitos socialmente, ou seja, os discursos são sempre determinados socialmente, eles não são neutros². Da mesma forma, a construção social de sentidos e valores concernentes ao corpo eà saúde também estão inseridos nessa trama discursiva que está além do sujeito que fala e reproduz a dinâmica da vida social.

No presente trabalho, iremos abordar al guns desses aspectos da construção de sentidos e articulação de discursos acerca do corpo a partir do estudo da atuação de al guns setores da medicina estética e das cirurgias estéticas. Este trabalho faz parte de uma pesquisa, iniciada em 2002, e contém trechos da tese de doutorado intitulada " $O \mathrm{~s}$ sentidos do corpo: cirurgias estéticas, discurso médico e saúde pública", defendida na Escola Nacional de Saúde Pública, em 2006³.

\section{O discurso da ciência}

A revolução científica iniciada no século XVI dá início a um processo social e uma concepção de ciência que perdura até hoje. Os princípios que nortearam o surgimento do método científico continuam a produzir verdades e a orientar con- cepções e teorias científicas que vão se mesclar à vida social, chegando até o senso comum. As relações sociais vão ser orientadas por essa racionalidadecientífica, quetudo explicae resolvecom seu discurso "neutro", racional e independente. Esse model o deracionalidade se constituiu tendo como modelo as ciências naturais e sendo um modelo global, a nova racionalidadeétambém um modelo totalitário, na medida em que nega o caráter racional a todas as formas de conhecimento que não se pautarem pelos seus princípios epistemológicos e pelas suas regras metodológicas ${ }^{4}$. Tal modelo se constitui a partir de uma lógica matemática que se torna 0 instrumento privilegiado de análise, assim como a investigação e a representação da própria estrutura da matéria. Sendo assim, conhecer significa quantificar e representar a partir de um modelo construído às vezes arbitrariamente.

Desde Descartes, conhecer implica desmembrar, classificar, eliminar 0 acidental eo aleatório, o que não podeser medido, dividido, quantificado e organizado dentro de uma lógica própria não podeser conhecido. Essa concepção, além de possuir uma base matemática, tem como referência um modelo mecanicista, funcional, que reduz tudo o que há no universo a relações mecânicas de causa e efeito ${ }^{5}$. Essemétodo propicia a formulação de leis gerais que poderiam explicar e controlar a natureza ea vida, as regularidades observadas permitiriam estabelecer as leis que fundamentariam o comportamento de todos os fenômenos, naturais ou sociais. A ciência moderna reduz a complexidade das coisas ese converte no modelo da racionalidade hegemônica que pouco a pouco se impõe não apenas no estudo da natureza, como também no estudo da sociedade 6 .

$M$ as este paradigma que nasce com Descartes e N ewton já não dá mais conta de explicar a realidade em sua totalidade e complexidade ${ }^{7}$. A hipótese de causalidade implícita nesse paradigmajá não é mais suficiente, nem necessária, para dar conta das incertezas do real. Desde Kant, já sabemos que o real éincognoscível e, desde H eisenberg e Bohr, já aprendemos que não é possível conhecer o real sem interferir nele, sem o alterar, e o próprio objeto do conhecimento se faz de acordo com o processo de conhecimento, eles não são neutros, nem o objeto nem o processo, muito menos o sujeito. 0 que conhecemos do real se dá a partir da intervenção que operamos nele, a partir das condições de observação, dos critérios de análise ou da seleção do objeto. 0 olhar do observador vai interferir decisivamente no processo ${ }^{8}$. 
A crisedesse paradigma dominantesefaz sentir a partir de vários ângulos, o modelo de causalidade, finalidade e relação mecânica já não dá mais conta de conhecer a natureza e, menos ain$\mathrm{da}$, a vida social. Simultaneamente, junto com a crise da ciência no século XX, se dá a percepção de que a autonomia da ciência, sua neutralidade e sua desvinculação dos problemas que afetam a vida social, não são fatores irrelevantes, externos, alheiosà realidadee desvinculados dosinteresses e conflitos das questões políticas e econômicas. Bourdieu ${ }^{9}$ afirma que o campo científico é um mundo social e, como tal, faz imposições, solicitações que são, no entanto, relativamente independentes das pressões do mundo social global queo envolve. $M$ as essa independência ésempre relativa, o grau de autonomia ou heteronomia de um campo se dá de acordo com a sua capacidade de negociação com o mundo exterior epeso político ou econômico na hora da decisão.

O campo científico é um campo de forças e, como tal, a dinâmica e a importância social de seus atores influenciam o que ele pode ou não fazer. É a posição que eles ocupam na estrutura social que determina ou orienta suas tomadas de posi ção $0^{10}$. A estruturação interna do campo pode ser determinada pela distribuição do capital científico dentro do campo, mas ela também sofre influência dos fatores externos. Desta forma, a racionalidade científica está impregnada das questões existentes nas suas bases sociais; ela sofre os efeitos políticos e econômicos de sua inserção na vida social, interage com eles.

A racionalidade moderna não se caracteriza por seu caráter contemplativo, pelo contrário, trata-se de um saber que propõe uma intervenção na natureza com a intenção de dominá-la, transformá-la, agir sobre ela. Seus conceitos e pressupostos reproduzem uma concepção de mundo mecanicista, dualista, quantitativista e ordenador. Ou seja, é um tipo de conhecimento que, ao interferir, modela, constrói a realidade, organiza segundo seus interesses, seus pressupostos e seus métodos; ele age no social embora isso nem semprefique explícito.

A medicina, quetem como objeto principal de estudo as relações entrea doença ea sociedade, é uma construtora de sentidos médicos, científicos e sociais ${ }^{11}$. Seu campo de atuação não se restringe ao domínio asséptico da ciência pura, ela extrapola e dissemina o seu saber para muito além de sua especialidade. D esta forma, a razão médica moderna expõe, na ordem da racionalidade científica, objetos de discursos que são de fato sociais. Te matiza, portanto, o social. É disciplina do social, disciplinadora de relações que são quase sempre sociais. As relações dos indivíduos e dos grupos sociais com seu corpo, seu sofrer, seu adoecer, sua morte, e com o corpo, o sofrimento, 0 adoecimento ea morte dos outros são relações sociais ${ }^{11}$.

Para M adel LuZ ${ }^{11}$, a medicina ea sociologia se confundem, pois ela atua em territórios queseriam estudados pela sociologia, ou pela antropologia, sendo que, enquanto a sociologia atua na macroestrutura, nas relações sociais, a medicina atua na microestrutura, no indivíduo. A medicina age não apenas no seu campo específico, mas irradia conceitos, verdades, parâmetros e sentidos por todo o corpo social; seus conceitos interferem na regulação de vários aspectos da vida social, seu discurso vira norma. A medicina não apenas participa da vida social e das forças produtivas, como também modela a própria vida social, fornece o modelo de percepção e construção de sentidos, valores, hábitos e processos cognitivos. "Naturaliza" o que é eminentemente social. 0 que é considerado natural vai ser reconduzido à ordem da razão. Ela é quem vai determinar esse novo conceito de natureza, mas não se trata de uma razão qual quer, trata-se da racionalidade científica que, como acabamos de ver, possui critérios próprios e rígidos para estabelecer e controlar a "natureza".

Essa racionalidade possui "ordens de sentido" que produzirão verdades específicas, disciplinas científicas econhecimentos sofisticados que nortearão o senso comum e formularão processos cognitivos que vão dar sentido à realidade, em qualquer instância, seja ela científica ou não. Ela funcionará como espinha dorsal da estrutura simbólica e cognitiva da vida social, ela équem dirá o que é correto ou não, coerente ou não, "natural" ou não, ou seja, essa racionalidade dirá o que pode ser considerado verdadeiro, coerente e confiável. E o queficar fora dela corre o risco de ser desqualificado, pois ela é a voz da verdade. Ou seja, o queéconsiderado natural, racional ou social se confunde e se funde numa argamassa que, em última análise, vai ser modelada pela mão da razão, melhor dizendo, da razão ancorada na ciência e nas suas verdades.

A racionalidade moderna, que é a origem de todo esse processo, se constitui principalmente como uma estrutura de explicação, uma forma específica de compreensão da realidade, de explicação do ordenamento do mundo que regula os princípios, os val ores, os corações eas mentalidades. A ciência moderna émais que uma forma de desvendamento do mundo. Elaé, sobretudo, uma forma de "ordenação" do mundo; deste modo, a 
percepção do corpo humano como uma máquina éconstruída a partir dessa lógica, que abarca a "natureza" com seus conceitos, próprios da racionalidade científica, e naturaliza seu discurso no seio da vida social. Trata-se de uma cosmovisão que produz sentidos, cria realidades etransforma essas realidades em verdade única eindiscutível ${ }^{6}$.

Para o senso comum, a matéria que constitui o corpo eo pensamento quelhe dá suporteainda éconcebida na perspectiva dualista emecanicista do pensamento moderno. 0 corpo geralmenteé visto como uma máquina que pode ser reciclada, aperfeiçoada ou "modernizada". 0 conhecimento científico queé divulgado e popularizado reforça esse modelo e se impõe como o "discurso verdadeiro", sem revelar suas ambiguidades, seus conflitos e seus limites. As metáforas mecanicistas da racionalidade moderna reaparecem hoje travestidas de tecnologia informacional eo "corpo-máquina" de La M ettrie ${ }^{12}$ (1709-1751) voltaà cena, sendo queagora eleéum híbrido de tecnologia computadorizada, carne e chips, matéria e megabytes de memória. 0 mito do corpo como máquina que obedece ao nosso comando ainda teima em persistir.

Segundo o pensamento dominante, hoje, 0 corpo não precisa mais ser obediente e fiel à natureza, ele pode se tornar mais "natural" do que o que a própria natureza concebeu. A tecnologia desenvolvida pela racionalidade científica e os valores e sentidos produzidos no mundo social agora constroem um corpo que nem a mãe natureza foi capaz defazer ${ }^{13}$. A indústria da estética vai dizer (deforma racional, científica) como tornar o seu corpo mais que perfeito, melhor que o projeto natural, obedecendo ao que se espera no mundo social. A indústria da metamorfose corporal possui a tecnologia adequada a cada situação, corpo ou bolso. Ela propõe uma transformação total da forma sem perceber, ou melhor, se esquecendo das ambiguidades elimites do sujeito. 0 corpo, por sua vez, não precisa mais ser dócil emoralmentecomportado, elepode atéser imoral, desde que seja belo e magro ${ }^{14}$, construído a partir de uma dieta e de uma vida "natural" e, quando necessário, a tecnologia pode dar uma força à natureza, melhorar o que ela não foi capaz de realizar.

Essa racionalidade que transforma tudo em valor monetário, mensurável, pragmático eutilitário vai virar de ponta cabeça mesmo os valores morais mais tradicionais. A sensualidade, quejá foi inimiga da razão científica natural e da razão da moralidade cristã, religi osa ou laica, e poderia levar ao erro e à decrepitude, hoje é vista como aliada preferencial do mercado, componente essencial na ordenação da vida social. O s sentimentos, as paixões, os desejos, os sentidos atribuídos ao corpo levam em consideração o componente sensual e a consequente ampliação de possibilidades no mercado profissional ou sexual, fazendo com que o que antes era visto socialmente como abominável, hoje seja visto como aceitável, desde que ajude a conseguir seu objetivo de ascensão social, otimize as possibilidades de sucesso econômico e aceitação social. A moral se torna mais flexível, os valores éticos idem, a esté tica também se adapta e oferece novos parâmetros, no corpo se incorporam os novos sentidos e a "saúde" se adapta.

Algumas práticas e sentidos relativos ao corpo ganham espaço e permitem a aproximação de valores sociais e éticos relativos ao corpo, à estética e saúde, possibilitando o surgimento de movimentos que visam modelar o corpo, adequando-o às normas sociais ${ }^{15}$ (através do culto ao corpo, fitness, cirurgias estéticas, prática de esportes radicais, modelagem do corpo, etc.).

A saúde passa, então, a ser um guarda-chuva simbólico no qual tudo cabe, ter saúde não se restringe a evitar as doenças, a "preservar-se", a "não correr riscos", a permanecer na normalidade médica. Ter saúde passa a ser igualmente cuidar da forma, do peso, da aparência (da pele, das rugas, dos cabelos brancos), da alimentação, da dieta ou do cuidado com as calorias, da manutenção da beleza e dajuventude. O scuidadoscom a estética passam a influenciar os cuidados com a saúde e com a "forma física". As relações de trabaIho também são influenciadas por essa perspectiva, a empregabilidade passa a ser diretamente ligada à aparência física. A preocupação com a estética passa a ser não apenas uma forma de manter a aparência ou a saúde, mas também uma forma de distinção social, garantia da manutenção do seu lugar no mercado de trabalho, no "mercado de trocas" sexual ou até mesmo como forma de conquistar a mobilidade social.

A estetização da saúde e da vida cotidiana permite o crescimento de diversas atividades comerciais ligadas às indústrias da estética, da cosmética e da metamorfose, para atender a uma demanda crescente, oferecendo serviços, medicamentos, equipamentos, profissionais (qualificados ou não), financiamentos, seguros, atividades físicas (esportivas ou recreativas), publicidade na grande imprensa, revistas especializadas, spas e hotéis especializados em tratamento estético, ou seja, os interesses comerciais desse setor não devem ser menosprezados. 
Segundo Sheila Lobato ${ }^{16}$, diretora da Lobato M erlin Editores, em matéria publicada no jornal Folha de São Paulo, em 13 de outubro de 2003, no Brasil, a indústria de cosméticos emprega 2,2 milhões de pessoas, o dobro do número empregado em 1994, e aumentou $74,5 \%$ seu faturamento líquido entre 1997 e 2000. Existem cerca de 1.200 empresas atuando no mercado de higiene pessoal, perfumaria e cosméticos, sendo catorze de grande porte, com faturamento líquido acima de $\mathrm{R} \$ 100$ milhões ao ano. A taxa de empregos no setor cresce à taxa anual de $10,6 \%$, acumulando 102,3\% de 1994 a 2001. As exportações de 1997 a 2001 saltaram deU S \$78,6 milhões para US\$146,7 milhões. No acumulado de 1997 a 2001, o PIB cresceu 10,4\% eo setor de cosméticos cresceu 56\%. O faturamento líquido saltou de $R \$ 5,5$ bilhões, em 1997, para R $\$ 9,6$ bilhões em 2002. Segundo matéria deTalita Figueiredo ${ }^{17}$, na pesquisa "O impacto socioeconômico da beleza. 1995 - 2005", da Universidade Federal Fluminense, também publicada no jornal Folha de São Paulo, em 13 de janeiro de 2006, o total de profissionais ocupados em higiene pessoal no Brasil é de 1.042.748 em 2005, enquanto que em 1985 era de 361.813. O Brasil é considerado o quinto maior mercado de cosméticos do mundo. Com o crescimento recente da economia e com o aumento do poder de compra das camadas médias da população, podemos imaginar que este setor tenha também obtido um crescimento considerável.

Para Guattari ${ }^{18}$, a subjetividade é essencialmente fabricada emodelada no registro do social, e é aí, no social, que o corpo vai se tornar um objeto a se moldar de acordo com um modelo ideal. 0 caráter pragmático de al guns setores da sociedade atual induz um número crescente de pessoas a buscar uma solução rápida para resolver a demanda por um corpo ideal. A modificação dos hábitos alimentares, o investimento em exercícios físicos e as mudanças comportamentais são sempre uma barreira, um investimento a longo prazo que não combina com o imediatismo dominante. Fazer uma cirurgia que resolve todos os problemas de imediato parece ser um caminho muito mais atraente.

Segundo pesquisa da Gallup Organization ${ }^{19}$ encomendada pela SBCP (Sociedade Brasileira de Cirurgia Plástica), no Brasil, em 2004, foram realizadas um total de 616.287 cirurgias plásticas (sendo 365.698 estéticas e 250.598 reparadoras) e, em 2003, haviam sido realizadas um total de 621.342 (sendo 374.271 estéticas e 247.071 reparadoras). Esses números colocam o Brasil como o segundo mercado em número de cirurgias plásticas no mundo, perdendo apenas para os Estados Unidos, onde há cerca de 800.000 procedimentos por ano. Ou seja, se mantivermos a média anual, teremos mais de 1.000 .000 decirurgias estéticas a cada três anos.

\section{Os sentidos do corpo mais que perfeito}

Atualmente, na medicina estética, os conceitos de beleza, saúde, corpo saudável e corpo belo vão ganhar outros contornos, outros sentidos, o discurso acerca do corpo "perfeito" vai trazer à tona essa estratégia de uma racional idade que atua na construção de um olhar que constrói cientificamente, modela, torna o corpo "naturalmente" belo. A doença agoraé construída, ela éuma projeção, uma imagem idealizada que não se confirma, uma construção fantasmática que gera dismorfia ${ }^{20}$. 0 que é considerado normal ou patológico muda de eixo.

As exigências da vida contemporânea têm gerado uma insatisfação crescente com relação ao corpo. São inúmeros os medicamentos que regulam o humor e a química corporal, fazendo do corpo um campo de testes de produtos químicos que regulam a relação afetiva das pessoas com o mundo, que, mesmo sem estar doente, tomam remédios para dormir, para ficar acordados, ficar em forma, tornar-se enérgico, meIhorar a memória, o rendimento, a performance sexual, suprimir o estresse, a ansi edade, regular a depressão, aumentar a capacidademuscular, controlar a fome, a tristeza ou a alegria. Ou seja, o corpo, com sua configuração atual, não corresponde às expectativas e exigências da vida, tornando-se necessário o uso destas próteses químicas para torná-lo uma máquina confiável21. 0 corpo é pensado como uma matéria indiferente, o simples suporte material para o sujeito, um objeto à disposição que pode ser melhorado de acordo com as expectativas do seu dono e, com isso, atender às exigências do mundo social. $\mathrm{E}$ a biotecnociência estaria disponível para operar a transformação.

Da mesma forma, o design corporal nem sempre corresponde às expectativas dos sujeitos. As cirurgias plásticas, as próteses estéticas e mecânicas, os processos de construção do corpo, as marcas corporais e o transexualismo moldam 0 corpo de acordo com o desejo de seus donos. $\mathrm{N}$ ão há limite para a metamorfose corporal e aquele corpo, antigo e precário, passa a ser objeto de investimento, recriação, ressignificação. 0 
corpo é o molde que se adapta às significações sociais, ele passa a encarnar os significados do mundo, reproduz seus símbolos e marcas de distinção e identidade ${ }^{22}$, criando signos que tanto funcionam como linguagem de revolta como de adaptação às regras, quetanto questionam quanto reforçam os valores do mundo ocidental.

A anatomia deixou de ser algo definitivo e passou a ser provisória, de acordo com a moda da ocasião. 0 corpo passa a ser um esboço, um rascunho a ser aperfeiçoado de acordo com 0 desejo e o bolso do cliente. Esta pretensão à perfeição também fica nítida no crescimento acelerado da tecnologia que tenta controlar os processos de fecundação in vitro, da gravidez fora do útero e de processos deinseminação artificial. O mito do filho perfeito, planejado com a ajuda da medicina ecom selo degarantia morfogenética, fabricado fora do corpo, à margem da sexualidade e fora de qualquer relação com o outro é também um dos sintomas da obsolescência do corpo, ou da tentativa de ampliar seus limites. 0 corpo da mulher se torna o laboratório onde se produz não apenas a tecnologia reprodutiva de ponta, mas também, uma nova antropologia; 0 corpo passa a ser um detalhe biológico tecnicamente controlável. Laboratório onde se redesenha a condição humana, a sexualidade, a procriação, o corpo, a infância, a filiação, a geneal ogia, a maternidade, a paternidade, o casal, a ligação social e até mesmo a vel hice e a morte ${ }^{21}$.

No final do século XIX, uma das questões apontadas pela nascente psicologia era a problemática da histeria, que se caracterizava por sintomas de ordem somática, tais como nevral gias, anestesias e paralisias, convulsões, vômitos, etc. Os sintomas histéricos seriam a expressão simbólica de um conflito cujas raízes estariam na história do sujeito ${ }^{23}$. Os sintomas corporais seriam efeitos de processos psíquicos que, de certa forma, podem traduzir 0 conflito indivíduo $x$ sociedade daquela época. No final do século XX, em nossa sociedade, o culto ao corpo, a obsessão com a forma física e com as dietas, a dismorfia corporal, os distúrbios alimentares (bulimia, anorexia e obesidade), os processos de construção do corpo (por meio de práticas esportivas, medicamentos, próteses, etc.), a percepção dos limites do corpo e as tentativas de ampliá-lo, a paixão pelos esportes radicais ${ }^{24}$ e a possibilidade de metamorfosear o corpo por meio de cirurgias plásticas (corretivas ou estéticas), próteses ou marcas identitárias estão na ordem do dia. São os sintomas do nosso tempo e apontam para uma nova identidade corporal a ser construída.
0 desenvolvimento acelerado da biotecnociência, a produção de sentidos no mundo contemporâneo e as transformações nas lógicas sociais estão alterando o estatuto do corpo, tornando possível ou tentando fazer crer queépossível operar a metamorfose do corpo de forma rápida e indolor. Narcisismo, hedonismo, individualismo econsumo estão entreos fatores propulsores de tais transformações, cujas consequências começam a delinear um quadro preocupante para a Saúde Pública. Alguns setores da classe média são seduzidos por promessas de uma beleza idealizada que pode vir a se tornar imediata, geralmentesem muito esforço por parte do cliente, em suaves prestações mensais. Essa pseudo democratização da tecnologia que permite operar a metamorfose corporal leva a conclusões precipitadas de que o processo ésimples, rápido, fácil e com riscos cada vez menores.

A imagem do corpo carrega a encarnação simbólica do sujeito desejante com suas histórias, sensações erógenas arcaicas e sua memória inconsciente relacional25. Alterá-la significa correr o risco de criar-se uma cisão no sujeito ou criar uma insatisfação às vezes desnecessária. Além da possibilidade de ocorrer um erro médico, pode acontecer de que, mesmo a metamorfose sendo bem-sucedida, o sujeito entra em um processo de negação do próprio corpo, de sua "imagem corporal"26 que certamente afetará sua saúde mental eseu bem-estar. 0 investimento libidinal em um corpo idealizado pode se tornar um tiro que sai pela culatra, criando ou agravando um quadro psíquico que, caso o sujeito não esteja emocionalmente maduro ou seguro, pode trazer sériosinconvenientes.

O controle sobre o corpo exercido pela sociedade vai "ao encontro" dos interesses do mercado (moda, mídia, publicidade, etc.) e da indústria da metamorfose (cirurgias, tratamentos, equipamentos e medicamentos com fins estéticos), criando novos sentidos enecessi dades para os "consumidores". Por outro lado, pode ir "de encontro" às questões psíquicas dos sujeitos, caso suas metamorfoses sejam malsucedidas, gerando transtornos nem sempre aparentes, já que os corpos não são dóceis e escapam em parte às estratégias de dominação. Desta forma, às vezes, a afirmação da vontade própria e legítima dos sujeitos pode também levar à criação de corpos hipocondríacos, paranóicos, esquizos, catatônicos, drogados, masoquistas, costurados, vitrificados, etc. ${ }^{27}$.

As exigências crescentes da vida contemporânea colocam o corpo como um objeto obsoleto 
que necessita de próteses mecânicas, químicas e farmacológicas para "dar conta do recado". 0 corpo não é mais sagrado, ele pode ser profanado, alterado, modificado, ampliado, reduzido ou substituído em partes, "trabalhado" nas academias, reconfigurado ereproduzido artificialmente. Assim como no mundo virtual, cada vez mais o corpo real vai sendo transformado em pura objetivação mercadológica, produção fantasmática objetificada, pura imanência do desejo ${ }^{28}$.

$N$ ão devemos aqui fazer juízos de valor nem negar os benefícios advindos das cirurgias plásticas (tanto corretivas quanto estéticas). M as cabe a nós, profissionais de saúde, chamar a atenção para a forma banalizada como tais cirurgias têm sido divulgadas e propor uma discussão que leve em conta os aspectos positivos e negativos da questão, de modo a tornar claro para a sociedadenão apenas os ben efícios ( como tem sido feito até agora), mas também os riscos possíveis, as implicações emocionais, as consequências indesejadas, as sequelas, enfim, uma escolha consciente que implica ônus e bônus.

A preocupação crescente com a forma física e o culto ao corpo fizeram com que o acesso a esses serviços fosse ampliado significativamente. Um estrato da população que, até pouco mais de uma década atrás, não cogitava fazer uma cirurgia estética, hoje não só tem acesso a esse tipo de serviço como também vêna utilização desses serviços um símbolo destatus, distinção eascensão social.

No decorrer da nossa pesquisa, foi possível perceber alguns fatores que interferem no campo das cirurgias estéticas, entreeles o crescimento da concorrência nesse setor, a diminuiç̧ão dos valores cobrados, a migração de médicos oriundos de outras especialidades que passaram a atuar neste campo, o surgimento delinhas de crédito, as facilidades oferecidas por esse mercado, o surgimento de mercado editorial especializado e a forma como a grande imprensa trata a questão.

No campo profissional, podemos perceber que as cirurgias plásticas, estéticas ou corretivas, passaram a ser vistas como filão de mercado profissional, gerando uma procura maior por parte dos recém-formados e a migração de profissionais anteriormente ligados a outras áreas, gerando uma competição mais agressiva dentro do campo (como o otorrino que faz rinoplastia, o ginecologista que faz uma abdominoplastia ou o oftalmologista que faz uma correção nas pálpebras). Paralelamente, percebemos o crescimento dos casos de dismorfia (ou dismorfobia) corporal, dos casos de bulimia, anorexia, obesidade ou outras doenças ligadas à imagem corporal e, ainda, a mudança no enfoque relativo à obesidade, o crescimento das cirurgias corretivas póscirurgia de redução de estômago ou o florescimento dos regimes radicais e do consumo dos moderadores de apetite.

É preocupante também o escamoteamento de problemas ocorridos durante as cirurgias, inclusive com falecimentos; o crescimento do número de denúncias e processos de erro médico no setor; o surgimento e crescimento de atividades financeiras ligadas ao setor, como financiamentos, seguros e promoções; a fronteira indefinida entrecirurgia estética ecorretiva; o papel do setor público e sua relação com o setor privado, na medida em que o Estado paga uma cirurgia corretiva fruto de um erro médico oriundo do setor privado; os problemas relativos às próteses etestes de moldagem no implante de silicone nos seios; uso de produtos estéticos que, comercializados livremente no Brasil, têm comercialização proibida ou restrita em outros países; as questões jurídicas relativas às cirurgias (a polêmica entre atividade fim ou atividade meio). $\mathrm{Ou}$ seja, as implicações e as complicações decorrentes dessa forma de "pensar a saúde", por meio de parâmetros estéticos e, principalmente, utilizando processos cirúrgicos, são inúmeras.

\section{O corpo, seussentidos \\ e o discurso na medicina estética}

0 discurso é um acontecimento sócio-histórico no qual a sociedade se revela, expondo suas ambiguidades, suas contradições, seus interditos, seus valores, conflitos e interesses presentes em cada campo de práticas. Sabemos que não há discurso sem sujeito e não há sujeito sem história e sem ideologia ${ }^{1}$. Por meio do discurso dos atores do campo da medicina estética, podemos observar a compreensão que tanto profissionais quanto usuários fazem dos cuidados com o corpo e a saúde.

Este forma dualista de pensar disseminada socialmente implica a percepção do corpo enquanto máquina a ser consertada, objeto a ser modificado ou melhorado, ou coisa distante, como se o corpo fosse um "outro" com o qual não houvesse identificação, uma percepção mecânica das partes sem considerar o todo, reproduzindo um olhar tecnicista, que reproduz valores oriundos do discurso médico hegemônico, reafirmando a obsolescência do corpo e a necessidade de aprimorá-lo, modernizá-lo, adequáIo às novas exigências. Este olhar mecanicista 
privilegia uma perspectiva técnico-científica, amparada pela lógica do mercado, em detrimento de uma atitude crítica diante do mundo.

Para compreender o discurso médico acerca da estética ou dos sentidos do corpo, não se deve ficar apenas no discurso médico, se fechar em um único circuito, pois esse discurso é constituído pelos discursos vizinhos, paralelos, concomitantes ${ }^{1}$. Os acontecimentos discursivos são influenciados pelos acontecimentos não discursivos como a cultura, a política, a moral, a ética, a arte, a filosofia, a ciência, a ideologia, enfim, instâncias aparentemente independentes que se encontram de alguma forma e trocam influências para a formação dos padrões de beleza, dos sentidos acerca do corpo e do olhar médico que vai interferir no corpo.

Desta forma, podemos perceber o percurso dos discursos e identificar suas posições éticas e políticas. Não se trata de tomar uma enunciação deslocada no tempo e no espaço e sim de identificar a materialidade constitutiva do enunciado a partir de uma perspectiva institucional, não apenas uma fala emitida isoladamente, mas um conjunto de enunciados que formam um discurso que traduz uma tomada de posição institucional, que diferencia certos sujeitos de fala dos outros sujeitos do campo. Se o discurso científico não é neutro, o discurso oriundo de setores da medicina estética, ligado a interesses mercantis diversos, muito menos.

A medicina estética opera um deslocamento na medida em que inscreve na superfície corpórea um "problema" que existia apenas na imaginação ou no meio social. A linguagem transforma o invisível em visível, estrutura-se como conhecimento que transcende 0 corpo para transformá-lo em corpo ideal. Trata-se de uma ruptura com a medicina tradicional, cujo modelo éo da clínica, que localiza no corpo o seu campo de ação, neleea partir del ${ }^{29}$. Essa medicina, ao contrário, se inscreve na superfície do corpo a partir de critérios subjetivos que estão fora dele, adota padrões estéticos que habitam a órbita da cultura, no território impreciso einconstante da moda. $E$ a ferramenta que orienta essa passagem e faz a ponte entre médicos e pacientes é o território igualmente impreciso da linguagem.

Os parâmetros de beleza, do queéreconhecido socialmente como belo, a imagem do próprio corpo, a construção da identidade a partir da imagem do corpo, os valores e sentidos atribuídos ao corpo constituem um território impreciso que recebe influências das mais diversas de toda uma rede discursiva que atua no social e envolve os sujeitos. Tal rede de sentidos evalores institui o que é valorizado socialmente e o que foge aos padrões dominantes passa a ser visto como inadequado, imperfeito ou, no mínimo, problemático. E a construção de sentidos acerca do corpo não é necessariamente a mesma entre profissionais e usuários, nem sempre eles falam a mesma linguagem ou constroem os mesmos sentidos.

A medicina estética utiliza de forma diferenciada a relação entre doença, signo e sintoma, pois a doença (ou a deficiência estética) é algo construído artificialmenteno âmbito da cultura, ela não está no corpo, mas se inscreve nele, começa a fazer parte dele. A "eficácia simbólica"30 atua e, uma vez sendo dito que aquele formato de corpo é feio ou que aquele seio não é belo, se essa opinião vai ao encontro da insatisfação existente, dificilmenteaquele corpo ou o seio voltam a ser vistos como normais. A questão, então, não está apenas no corpo, mas na construção de sentidos que está na ordem da cultura e que é apropriada pelos discursos da publicidade, dos meios de comunicação de massa ou dos profissionais e instituições ligadas à medicina estética. Tais discursos atuam no senso comum e possuem uma eficácia simbólica bastante precisa, fazendo com quetais "defeitos" se inscrevam no corpo de fato.

0 senso comum, informado também pelos especialistas e pelas revistas especializadas, constrói um ideal de beleza queéreforçado, valorizado pelo discurso médico do setor, que reproduz um padrão estético hegemônico quenada tem de "natural" ou espontâneo. A beleza étratada como algo natural quando, na verdade, ela éuma construção social, não havendo beleza "natural" que não passe pela cultura ${ }^{31}$. Ela é o filtro que permite construir tais padrões "naturais" através das relações sociais e refletem em tais parâmetrosseus conflitos e sua dinâmica. Existe uma razão instrumental que desloca a questão e coloca tais critérios e parâmetros sob o seu domínio, opera a partir dos seus critérios, e a bel eza "natural" passa a ser construída artificialmente. Por sua vez, os meios de comunicação de massa e a indústria de consumo ligada às metamorfoses corporais atuam sem crítica, limitações ou aprofundamento de questões que consideramos importantes. Pensar de forma crítica nem sempre éagradável, não seduz enão vende, o espetacular vendemuito mais. Por outro lado, como pensar essas questões, no âmbito da Saúde Pública, com um mínimo de responsabilidade, seriedadee respeito com os usuários, sem cair em preconceitos ou juízos de valor? 
Hoje, a preocupação estética é introduzida cada vez mais cedo no universo infantil ou adolescente por meio dos produtos da indústria da moda, da indústria de cosméticos, medicamentos, dietas eculto ao corpo; o componente estético passa a ocupar um lugar de destaque na vida de homens e mulheres, gerando preocupações, angústias e um controle rígido acerca da imagem do corpo e da adequação dessa imagem às normas sociais. N unca se falou tanto em dieta, alimentos saudáveis, recomendáveis, alimentação (in)adequada, controle de calorias, índice de massa corporal, obesidade, anorexia, bulimia, dismorfia, ou seja, técnicas disciplinares, proce dimentos reguladores que incluem até as crianças no mundo dos cosméticos, produtos e tratamentos de beleza, controle alimentar, etc.

Da mesma forma que o controle rígido sobre a sexualidade tempos atrás produzia histeria e mal-estar, hoje, agindo por caminhos e estratégias diferentes, a preocupação estética comporta uma série de saberes, práticas e formações discursivas que trabalham de forma a "atualizar" 0 biopoder ${ }^{32}$, inscrevê-lo nas questões atuais. A doença e o doente não estão mais inscritos na ordem da doença tradicional. A doença passa a ser uma construção imagética traduzida em linguagem, fazendo com que a construção de uma imagem ideal se dê a partir de parâmetros que estão além do corpo, na ordem social.

Os valores eos sentidos acerca do corpo constroem um corpo ideal, mas um corpo ondea doença não está inscrita no seu interior, na sua materialidade, ela agora vem de fora, do âmbito da cultura e se inscreve no próprio corpo, vem do exterior e "cola" no corpo, é incorporada pelo sujeito que passa a perceber o seu corpo como doente, inadequado, insuficiente. 0 crescimento do mercado de cirurgias plásticas, da medicina estética, da indústria de cosméticos e da preocupação com os parâmetros estéticos colocados como referência para a "saúde" nos leva a acreditar quetal expansão não está sendo acompanhada de uma discussão séria acerca do significado real dessecrescimento. Em função disso, no nosso trabalho, investigamos os princípios que organizam este discurso e analisamos os enunciados de um dos setores da medicina ligados à estética, de modo a identificar essa construção de sentidos e a formação dessa racionalidade que coloca o corpo como objeto descartável, modificável e reciclável. Uma racionalidade que nem sempre respeita o sujeito.

\section{Referências}

1. Orlandi EP. Análise de discurso. Princípios e Procedimentos. Campinas: Pontes; 2003.

2. Foucault M. A ordem do discurso. São Paulo: Loyola; 1996.

3. Romão Ferreira F. Os sentidos do corpo: cirurgias estéticas, discurso médico e Saúde Pública [tese]. Rio de Janeiro: Escola Nacional de Saúde Pública; 2006.

4. Santos BS. Um discurso sobre as ciências. São Paulo: Cortez; 2004. p.21.

5. Koyré A. Os filósofos e a máquina. In: Koyré $A$. Estudos de História do Pensamento Filosófico. Rio de Janeiro: Forense Universitária; 1991.

6. Chauí M. Convite à Filosofia. São Paulo: Ática; 1999.

7. Morin E. Introdução ao pensamento complexo. Porto Alegre: Sulina; 2005.

8. Oliveira LA. Biontes, bióides e borgues. In: Novaes A, organizador. 0 homem-máquina. A ciência manipula o corpo. São Paulo: Companhia das Letras; 2003.

9. Bourdieu P. Os usos sociais da ciência: por uma sociologia clínica do campo científico. São Paulo: Unesp; 2004.
10. Bourdieu P. Para uma sociologia da Ciência. Lisboa: Edições 70; 2001.

11. Luz MT. Natural, Racional, Social. São Paulo: Hucitec; 2004

12. La M ettrie JO. L'homme Machine. Paris: Éditions Denoël/Gonthier; 1981.

13. Goldenberg M. Nu e Vestido - Dez antropólogos revelam a cultura do corpo carioca. Rio de Janeiro: Record; 2002.

14. Foucault M. Microfísica do poder. Rio de Janeiro: Graal; 1984.

15. Luz MT. Novos saberes e práticas na saúde coletiva. Estudo sobre racionalidades médicas e atividades corporais. São Paulo: Hucitec; 2003.

16. Lobato S. O poder da beleza. Folha de São Paulo 2003; 13 out.

17. Figueiredo T. O impacto socioeconômico da beleza. 1995 - 2005. Folha de São Paulo 2006; 13 jan.

18. Guattari F, Rolnik S. Micropolítica - Cartografias do desejo. Petrópolis: Vozes; 1999. 
19. Peixoto P. Pesquisa Gallup Organization. Folha de São Paulo 2005; 15 nov.

20. M onteiro AC. Espelho, espelho meu...: percepção corporal e caracterização nosográfica no Transtorno Dismórfico Corporal [dissertação]. Rio de Janeiro: ENSP; 2003.

21. Le Breton D. L' adieu au corps. Paris: Metailié; 1999

22. Le Breton D. Signes d'identité. Tatouages, piercings et autres marques corporalles. Paris: M etailié; 2002.

23. Freud S. 0 ego e o Id. Edição standard. Rio de Janeiro: Imago; 1977

24. Le Breton D. 0 fim do corpo. Jornal do Brasil 2001: 17 mar.

25. Dolto F. A imagem inconsciente do corpo. São Paulo: Perspectiva; 2001.

26. Shilder P. A imagem do corpo. São Paulo: Martins Fontes; 1994.

27. Deleuze G, Guattari F. Como criar para si um corpo sem órgãos. In: Deleuze G, Guattari F. Mil Platôs Capitalismo e esquizofrenia. Vol. 3. Rio de Janeiro: Ed. 34; 1996.
28. Le Breton D. Adeus ao corpo. In: Novaes A, organizador. 0 homem-máquina: a ciência manipula o corpo. São Paulo: Companhia das Letras; 2003.

29. Machado R. Ciência e Saber: a trajetória de Michel Foucault. Rio de Janeiro: Graal; 1981.

30. Lévi-Strauss C. A eficácia simbólica. In: Lévi-Strauss C. Antropologia estrutural. Rio de Janeiro: Tempo Brasileiro; 2003.

31. Eco H. História da Beleza. Rio de Janeiro: Record; 2004.

32. Foucault M. Naissance de la biopolitique. Paris: Gallimard; 2004

Artigo apresentado em 22/08/2007

Aprovado em 13/11/2007

Versão final apresentada em 30/11/2007 